\title{
A low-cost computer-controlled function generator suitable for generating visual grating displays
}

\author{
I. H. DURHAM and D. J. ILLINGWORTH \\ University of Western Australia, Nedlands 6009, Australia
}

\begin{abstract}
This paper reports a simple low-cost computer peripheral for generation of gratings. Its advantages are minimal CPU operations, reliability, and variety of programmable output functions.
\end{abstract}

The luminance gratings used in the study of human spatial and temporal vision can be generated in several ways. These include optical techniques (Antis \& Comerford, 1975) and electronic waveform generators for the Y-axis and Z-axis (e.g., Fischer, 1976; Hughes \& Snow, 1973; Shapley \& Rossetto, 1976; Stamps \& Bourne, 1972), coupled to a TV raster or cathode-ray oscilloscope (CRO) with a time base for the X-axis. Either analog (Rogers, 1976) or digital (Brown, 1977) techniques can be used to provide moving gratings. All the latter methods are related to the original technique described by Campbell and Green (1965). In addition, a microprocessor could be used as a scheduling device for switching peripheral generators (Keemink, van der Wildt, \& Van Deursen, 1979).

An alternative is to calculate the appropriate waveform for the Z-modulation profiles. Further, stimulus parameters can be preprogrammed. A microcomputerbased system reported by Fritsch and Keck (1978) uses the sequential digital-to-analog (D/A) output of a preprogrammed table to determine the modulation. There are some general disadvantages to all such methods. First, there is a tradeoff between quality of display (points plotted per sweep) and time-base speed (approximately $10 \mathrm{msec} / \mathrm{sweep}$ ). In general, low spatial frequencies are of better quality than are high frequencies. Thus, careful attention must be paid to interacting factors such as the optical transfer function of the CRO and the general testing conditions employed in a particular experiment. A related choice problem is the real-time task allotted to the computer. If the same computer is also monitoring behavioral and electrophysiological data, severe limitations are made on execution times. Either display quality suffers or the sampling grain must be increased; the same microcomputer cannot do both tasks. As an example, Fritsch and Keck (1978) report concurrent data acquisition with an analog-to-digital (A/D) conversion rate of 1 data item/sec. In many experiments, this rate is insufficient. An additional problem revolves around the software chosen for the task: A high-level language may not give adequate control over execution speed. Also, programming costs are a real but subtle overhead to the experimenter. Finally, a suitable algorithm would be both a more flexible and a more elegant solution.

This paper reports a simple-to-construct computercontrolled function generator that can be used for grating generation. As it is programmable, none of the flexibility that accrues to a real-time computer is lost. Its appeal comes from the variety of output functions and great reliability at very low cost.

\section{DESCRIPTION OF THE SYSTEM AND PERIPHERAL}

The system is based on a Computer-Automation ALPHA LSI-2 minicomputer (16 bits) with $16 \mathrm{~K}$ memory and dual floppy-disk system, and the CRO displays are Tektroniz 604 CROs with adjustable builtin horizontal time base (set for $100-\mathrm{Hz}$ sawtooth). A separate function generator provides a free-running vertical trace from a $1-\mathrm{MHz}$ triangle wave.

The computer controls the following functions to modulate the visual display: (1) $\mathrm{Z}$ waveform-sine, square, or triangular; (2) spatial frequency range - .25$20 \mathrm{cycles} / \mathrm{deg}$ with a subject seated $1 \mathrm{~m}$ from the display; (3) attenuation $-0--48 \mathrm{~dB}$ minimum; (4) phase reversal- $0-20 \mathrm{~Hz}$; and (5) switch signal between two oscilloscopes.

The current values of each function for the above display system are given, but alternative values are possible by adjusting various factors (detailed briefly below).

Figure 1 shows three latches loaded with the appropriate values so that the computer is free to perform other tasks until a stimulus change is required. For control protocol, each latch is considered an input/ output (I/O) port, with the "Device Select" lines being decoded outputs of the 8-bit port number. The control word governs waveform, and so on, by using the word in bit mode (see Figure 1). The signal generator chip is an EXAR (XR2206) (see Table 1); its frequency is determined by the output of a D/A converter connected directly to the VCO control (Pin 3). The frequencyselect word controls the D/A output voltage, which may 


\begin{tabular}{|c|c|c|c|}
\hline OUTPUT FUNCTION & ASSEMBLY LANGUAGE MNEMONIC & HEX COOE & VALUE RANGE \\
\hline \multirow[t]{2}{*}{ 1. FREQUENCY SELECT MORD } & LAP "XX" & $: c 6 x x$ & $0=0.25 \mathrm{C} / \mathrm{DEG}$ \\
\hline & OTA : $1 E, \varnothing$ & $: 6 \mathrm{CF}$ & $: F F=20 \mathrm{C} / \mathrm{DEG}$ \\
\hline \multirow[t]{2}{*}{ 2. ATTENUATION SELECT MORD } & LAP "XX" & $: \cos x x$ & $: F F=0 D B$ \\
\hline & OTA : 1E, I & $: 6 \mathrm{CF} 1$ & $0=-48 \mathrm{DB}$ \\
\hline \multirow[t]{2}{*}{ 3. CONTROL MORD } & LAP "XX" & $: \operatorname{cosx}$ & BIT 7 NOT USED \\
\hline & OTA : $1 E, 2$ & $: 6 \mathrm{CF} 2$ & $\begin{array}{l}\text { BITS 4-6 CONTROL } \\
\text { PHASE REVERSAL } \\
\text { BITS } 2,3 \text { SINE, SQUARE } \\
\text { OR TRIANGULAR WAVE- } \\
\text { FORM, BITS 0, I LEFT, } \\
\text { RIGHT OR BOTH CROS }\end{array}$ \\
\hline
\end{tabular}

BLOCK DIAGRAMME

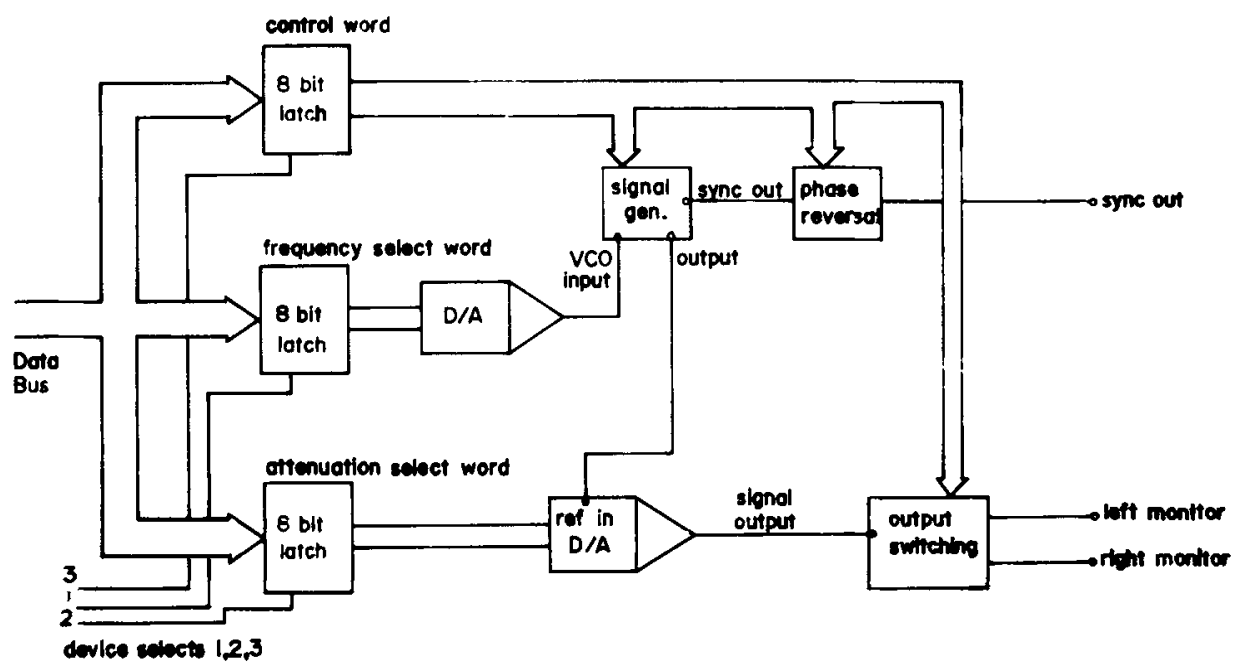

Figure 1. Program codes and block diagram for grating generator.

be changed even while a waveform is presented to the oscilloscopes. An 8-bit word gives 256 discrete "temporal" frequencies for a coverage between $100 \mathrm{~Hz}$ and $300 \mathrm{kHz}$. However, a more appropriate range can be selected by adjusting the EXAR chip frequency clock [i.e., by modifying the capacitor between Pins 5 and 6 (XR2206) and the resistor between Pin 7 (XR2206) and Pin 4 (DAC08)]. By applying the signal to the reference input of a multiplying D/A (e.g., PMI's DAC 08) (see Table 2), the maximum word (:FF Hex) will produce $0-\mathrm{dB}$ attenuation. Further steps up to

Table 1

Information on the EXAR (XR-22 06)

Monolithic Function Generator

\begin{tabular}{ll} 
Sine-Wave Distortion* & $.5 \%$ \\
Temperature Stability & $\pm 20 \mathrm{ppm} /{ }^{\circ} \mathrm{C}$ \\
Power Supply Sensitivity & $.01 \% / \mathrm{V}$ \\
Operating Temperature Range & $0^{\circ} \mathrm{C}-75^{\circ} \mathrm{C}$ \\
Amplitude Stability & $.5 \mathrm{~dB}$ \\
\hline
\end{tabular}

*Total harmonic distortion.
Table 2

DAC08 Ratings of Interest

\begin{tabular}{ll} 
Reference Input Slew Rate & $8 \mathrm{~mA} / \mathrm{microsec}$ \\
Propagation Delay (all bits switched) & $35 \mathrm{nsec}$ typo \\
Nonlinearity & $\pm .1 \% \mathrm{FS}$ \\
Settling Time & $85 \mathrm{nsec}$ \\
F.S. Tempco & $\pm 10 \mathrm{ppm} /{ }^{\circ} \mathrm{C}$ \\
\hline
\end{tabular}

$-48 \mathrm{~dB}$ are possible by adjusting the output voltage; that is, halving the output word halves the voltage. ${ }^{1}$

Phase reversal is shown in Figure 2. A wider selection of rates could be had by including Bit 7 in the resistive network, and in this way, 15 discrete reversal rates are available. Greater accuracy could be obtained by replacing the resistive network by a D/A converter.

\section{COMPUTER PROGRAM}

The required program is simple. The current one is written in assembly language, with output functions controlled by the bit pattern of an 8-bit word. Supple- 


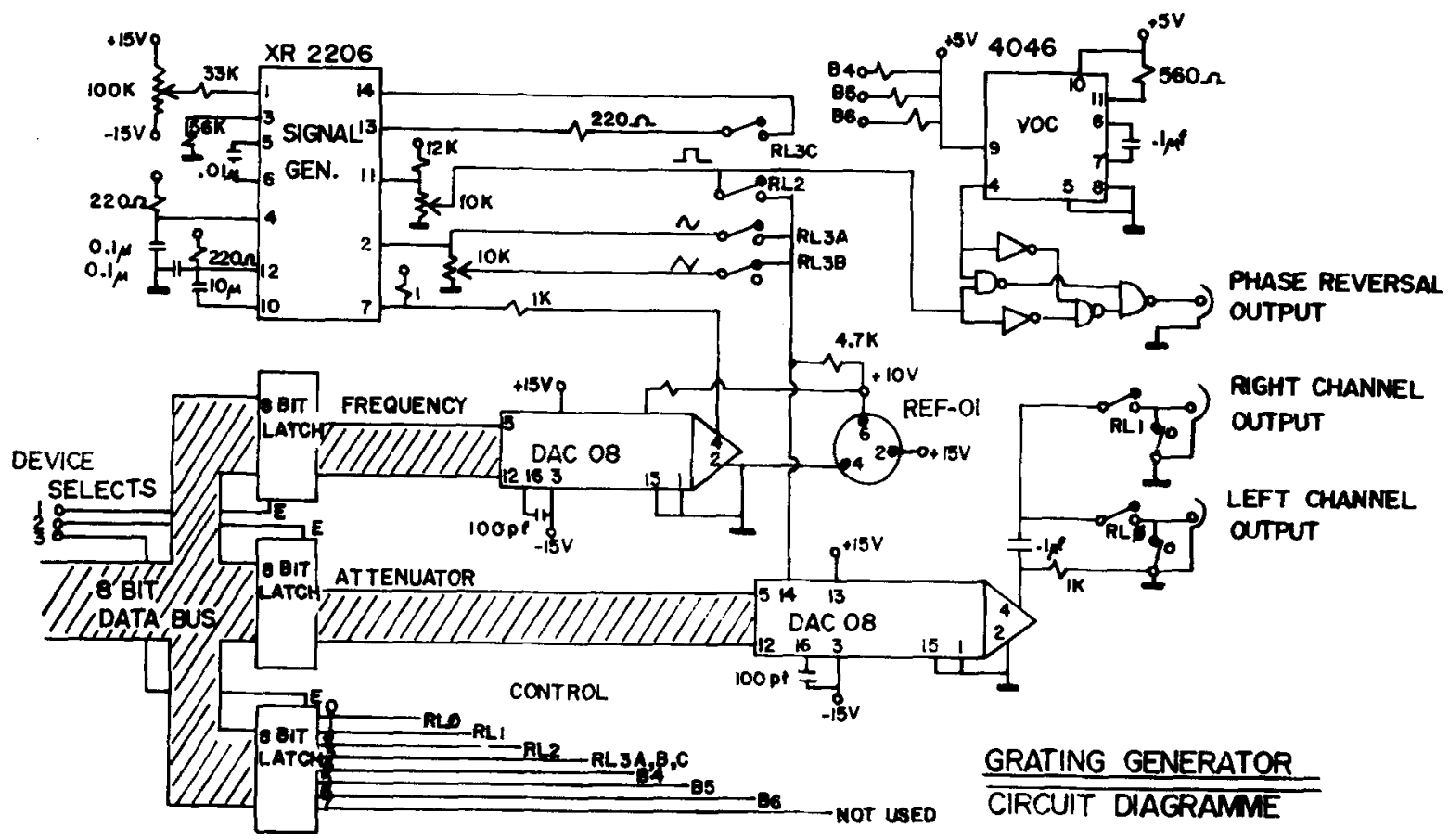

Figure 2. Grating generator: Circuit diagram.

mentary software can be written in a high-level language to give interactive control of parameters. Duration of the display is maintained by the computer real-time clock.

\section{DISCUSSION}

This paper was prompted by the need for a simple, cheap, and programmable computer peripheral to produce luminance gratings of varying spatial frequency, contrast, and phase reversal. Its reliability, flexibility, and ease of programming attest to its value. Finally, the circuit could be used in other applications (e.g., simply psychoacoustics). Estimated cost is approximately $\$ 60$, which covers all components, circuit board, and so on. Labor costs should be calculated on 1.3 days for a competent electronics technician.

\section{REFERENCES}

Antis, S. M., \& Comerford, J. P. A simple method of projecting Mach bands, colour mixtures and variable contrast sinusoidal gratings. Behavior Research Methods \& Instrumentation, 1975, 7, 283-287.

Brown, C. R. A digital technique for generating moving grating patterns on an oscilloscope. Vision Research, 1977, 17, 299-300.

Campeell, F. W., \& Green, D. G. Optical and retinal factors affecting visual resolution. Journal of Physiology, 1965, 181, 576-593.
Fischer, C. W. Electronics for a study of masking in spatial frequency channels. Vision Research, 1976, 16, 666-670.

Fritsch, D., \& KeCH, M. J. Grating generation by microcomputer. Vision Research, 1978, 18, 1083-1085.

Hughes, A., \& Snow, G. R. A visual stimulator employing a TV raster display. Vision Research, 1973, 13, 1187-1190.

Jung, W., \& Ritmanich, W. Get wide-ranged digitally controlled audio attenuation with a companding D/A. Electronic Design, 1978, 23, 92-96.

Keeminx, C. J., van der Wildt, G. T., \& Van Deursen, J. B. P. Microprocessor-controlled contrast sensitivity measurements. Medical and Biological Engineering and Computing, 17, 371-378.

Rogers, B. J. A technique for generating moving visual stimuli on a CRO. Vision Research, 1976, 16, 415-417.

Shapley, R., \& Rossetro, M. An electronic visual stimulator. Behavior Research Methods \& Instrumentation, 1976, 8, 15-20.

STAmp8, R. F., \& Bounne, J. R. Electronic production of shifting grid pattern displays. Vision Research, 1972, 12, 743-746.

\section{NOTE}

1. A greater range with a direct decibel scaling can be obtained with a companding D/A converter such as PMI's DAC 76 (Jung \& Ritmanich, 1978), which will provide an attenuation range of 0 to $-78 \mathrm{~dB}$. The "companding" $\mathrm{D} / \mathrm{A}$ converter was intended for inclusion in the circuit but was not available commercially at the time of construction.

(Received for publication June 18, 1980; accepted June 8, 1981.) 